\title{
Feeding barley grain-rich diets altered electrophysiological properties and permeability of the ruminal wall in a goat model
}

\author{
F. Klevenhusen, ${ }^{*}$ M. Hollmann, ${ }^{*}$ L. Podstatzky-Lichtenstein, † R. Krametter-Frötscher, $¥$ J. R. Aschenbach,§ \\ and Q. Zebeli*1 \\ *Institute of Animal Nutrition and Functional Plant Compounds, Department for Farm Animals and Veterinary Public Health, Vetmeduni Vienna, \\ Veterinaerplatz 1, 1210 Vienna, Austria \\ †Institute for Organic Farming and Biodiversity, LFZ Raumberg-Gumpenstein, 4600 Wels, Austria \\ $\ddagger$ Clinic for Ruminants, Department for Farm Animals and Veterinary Public Health, Vetmeduni Vienna, Veterinaerplatz 1, 1210 Vienna, Austria \\ §Institute of Veterinary Physiology, Free University of Berlin, 14163 Berlin, Germany
}

\begin{abstract}
High-producing ruminants are commonly fed large amounts of concentrate to meet their high energy demands for rapid growth or high milk production. However, this feeding strategy can severely impair rumen functioning, leading to subacute ruminal acidosis. Subacute ruminal acidosis might have consequences for electrophysiological properties by changing the net ion transfer and permeability of ruminal epithelia, which may increase the uptake of toxic compounds generated in the rumen into the systemic circulation. The objective of the present study was to investigate the effects of excessive barley feeding on the electrophysiological and barrier functions of the ruminal epithelium and serum inflammation and ketogenesis markers after a long-term feeding challenge, using growing goats as a ruminant model. A feeding trial was carried out with growing goats allocated to 1 of the 3 groups $(\mathrm{n}=5-6$ animals/group), with diets consisting exclusively of hay (control diet) or hay with 30 or $60 \%$ barley grain. Samples of the ventral ruminal epithelium were taken after euthanasia and instantly subjected to Ussing chamber experiments, where electrophysiological properties of the epithelium were measured in parallel with the permeability of marker molecules of different sizes [fluorescein 5(6)-isothiocyanate and horseradish peroxidase] from luminal to apical side. Additionally, ruminal fluid and blood samples were taken at the beginning of the experiment as well as shortly before euthanasia. Ruminal fluid samples were analyzed for volatile fatty acids and $\mathrm{pH}$, whereas blood samples were analyzed for lipopolysaccharide, serum amyloid A, and $\beta$-hydroxybutyrate. Electrophysiological data indicated that barley feeding increased the epithelial short-circuit current compared with the control. Tissue conductance
\end{abstract}

Received September 23, 2012

Accepted December 22, 2012.

${ }^{1}$ Corresponding author: qendrim.zebeli@vetmeduni.ac.at also increased with dietary barley inclusion. As shown with both marker molecules, permeability of ruminal epithelia increased with barley inclusion in the diet. Despite a lowered ruminal $\mathrm{pH}$ associated with increased volatile fatty acids (such as propionate and butyrate) concentrations as well as altered epithelial properties in response to high-grain feeding, no signs of inflammation became apparent, as blood serum amyloid A concentrations remained unaffected by diet. However, greater amounts of grain in the diet were associated with a quadratic increase in lipopolysaccharide concentration in the serum. Also, increasing the amounts of barley grain in the diet resulted in a tendency to quadratically augment serum concentrations of $\beta$-hydroxybutyrate and, hence, the alimentary ketogenesis. Further studies are needed to clarify the role of barley inclusion in the development of subacute ruminal acidosis in relation to ruminal epithelial damage and the translocation of toxic compounds in vivo.

Key words: Ussing chamber, short-circuit current, subacute ruminal acidosis, ruminal barrier

\section{INTRODUCTION}

The intensive production systems of ruminants encourage the inclusion of large amounts of cereal grains or easily degradable byproducts in the diet to support high milk yields or rapid weight gain. Although these feeding practices might be helpful to enhance cost efficiency in the short term, they do not comply optimally with the ruminant's digestive physiology. The most important consequence thereof is a disturbed rumen ecosystem, which is often perceived in the form of a prolonged decline in ruminal $\mathrm{pH}$ to acidotic values $<5.8$, a rumen metabolic disorder commonly referred to as SARA (Zebeli and Metzler-Zebeli, 2012).

Subacute ruminal acidosis is associated with important microbial and metabolic alterations that also affect the epithelial lining of the rumen (Penner et al., 2011). One of the crucial functions of the reticuloruminal epi- 
thelia is to maintain barrier integrity while regulating the selective absorption of VFA (Aschenbach et al., 2011). The barrier function of the rumen is particularly important in animals during long episodes of SARA to prevent translocation of the accumulated LPS or other potentially toxic compounds (e.g., enterotoxins and biogenic amines) into the systemic circulation (Ametaj et al., 2010b; Plaizier et al., 2012). Changes in the morphological and histological properties of ruminal papillae (Steele et al., 2009) as well as an increased permeability of the ruminal epithelium through deterioration of cellular junctions and thickness of this epithelium (Steele et al., 2011) have been reported during SARA insults. Under normal physiological conditions, the ruminal epithelium serves as a barrier and prevents the paracellular transport of toxic compounds into the blood circulation (Plaizier et al., 2012). However, at high acidity, as in case of SARA, high LPS concentrations and osmolality of the digesta can decrease the barrier function and increase the epithelial permeability, resulting in an increased uptake of LPS (Emmanuel et al., 2007; Khafipour et al., 2009a), which initiates an acute-phase response (APR). Serum amyloid A (SAA) is an acute-phase protein (APP) that participates in the neutralization of LPS during the process of APR (Emmanuel et al., 2008; Plaizier et al., 2012). Serum amyloid A was demonstrated to significantly increase during SARA in cattle (Gozho et al., 2006; Emmanuel et al., 2008; Khafipour et al., 2009a). Although the APR is regarded as a protective reaction of the body aiming to reestablish the disturbed homeostasis, in the long term, the inflammatory state has important implications for animal health and production efficiency (reviewed by Zebeli and Metzler-Zebeli, 2012).

Despite the importance of barrier function for systemic health, little data exist evaluating the effects of high-grain feeding and SARA on the electrophysiological characteristics and barrier function of the ruminal epithelium. Most of the studies conducted so far have evaluated the effects of in vitro acidic medium on the functionality of ruminal epithelia (Aschenbach and Gäbel 2000; Emmanuel et al., 2007; Penner et al., 2010). Although these in vitro data serve as indications for implication of SARA in the changes of ruminal epithelial properties, these experiments cannot replace in vivo conditions. Consequently, a need exists to examine whether individual changes in the diet (i.e., higher concentrate level/low fiber content), are involved in the electrophysiological changes and barrier function of the ruminal epithelia.

The objective of the present study was to evaluate changes in the electrophysiological properties and barrier function of the ruminal epithelium, using growing goats after a long-term feeding challenge of excessive amounts of barley grain as an in vivo ruminant model. Long feeding periods are crucial to explain potential dietary effects on the functionality of the ruminal epithelia under in vivo conditions. Ruminal $\mathrm{pH}$ and the concentration of VFA were measured in the ruminal digesta to evaluate the fermentation characteristics in vivo and relate it to findings obtained in the Ussing chamber experiments. Additionally, clinical signs were evaluated and serum SAA and BHBA were used as indicators of APR and ketogenesis, respectively.

\section{MATERIALS AND METHODS}

\section{Animals, Housing, and Feeding Trial}

The animal experimentation protocol of this research was approved by the institutional ethics committee of the University of Veterinary Medicine Vienna in accordance with Good Scientific Practice guidelines and national legislation (Protocol no. 15/03/97/2011). For the feeding trial, 1 female and 17 noncastrated male growing goats (6 Boer breed, 6 White German Noble breed, and 6 Toggenburg breed) were used at the experimental station of the Institute for Organic Farming and Biodiversity in Wels, Austria. Upon arrival, all goats were treated for internal parasites with Hapadex $5 \%(1.5 \mathrm{~mL}$ of netobimin $/ 10 \mathrm{~kg}$ of $\mathrm{BW}$; Intervet $\mathrm{GmbH}$, Vienna, Austria). Upon the commencement of the experiment, the goats were between 3 and 4 mo old and ranged between 13 and $22 \mathrm{~kg}$ in BW. Prior to the experiment, goats consumed a high-forage diet of 1.5 $\mathrm{kg}$ of meadow hay (second cut) and $200 \mathrm{~g}$ of hammermilled barley grain per animal and day (as-fed basis) for a period of $2 \mathrm{wk}$.

After this adaptation period, the animals were gradually switched to the experimental diets, which they received for another 6 wk. Due to health problems, 1 animal had to be removed from the experiment. Animals were allocated in a blocked, randomized design, balanced for weight and breed, to 1 of 3 treatments consisting of either pure chopped hay, considered as the control (CTR) diet $(\mathrm{n}=5)$, or a low-barley $(\mathbf{L B})$ diet containing $30 \%$ barley grain and $70 \%$ hay ( $\mathrm{n}=$ 6), or a high-barley (HB) diet containing $60 \%$ barley grain and $40 \%$ hay $(\mathrm{n}=6$; Table 1$)$. It has been shown in dairy cows that diets including the rather moderate amount of $30 \%$ barley can already increase ruminal LPS and plasma SAA concentrations (Emmanuel et al., 2008). Diets containing $60 \%$ grain were shown to induce SARA in dairy cows (Steele et al., 2011) and were considered to cause changes in the epithelial barrier function. Accordingly, we chose the 2 levels 30 and $60 \%$ to compare them with a control treatment containing no barley to investigate the effects of dietary barley in- 
clusion on the ruminal epithelium in a dose-dependent manner. Meadow hay (second cut) fed in this experiment originated from one single batch. Barley grain fed in this experiment was also from one single batch and hammer milled; barley was selected as the cereal grain due to rapid degradation of its starch in the rumen and, hence, due to its high potential to cause an acidotic insult (Zebeli et al., 2008). Goats were transitioned to the 30 and $60 \%$ grain diets by gradually increasing the dietary grain level by 2.5 and $5 \%$ per day, respectively. Feed was provided in individual feeding troughs twice daily at 0630 and $1330 \mathrm{~h}$. A mineral lick stone (Alpenleckmasse für Rinder: $\mathrm{Ca}, 12 \%$; P, $6 \%$; Na, $5 \%$; Mg, $2 \%$; Zn, 6,000 mg; Mn, 2,000 mg; Cu, 1,000 mg; I, $40 \mathrm{mg}$; Se, 40 mg; GARANT Tiernahrung GmbH, Pöchlarn, Austria) and a salt lick stone (Biosaxon Salzleckstein: sodium chloride, Na minimum: 39\%; GARANT Tiernahrung $\mathrm{GmbH}$ ) and water were provided ad libitum. Goats were fed restrictively with a daily feed allowance of about $650 \mathrm{~g}$ per goat (as-fed basis) at the commencement of the experiment. Goats were weighed every week to adjust the feed allowance. The feed amount was calculated to meet energy and nutrient requirements for maintenance and to account for $250 \mathrm{~g}$ of BW gain per week of goats fed the CTR diet (Gesellschaft für Ernährungsphysiologie, 2003). After $6 \mathrm{wk}$, the animals were transferred to the University of Veterinary Medicine Vienna, Austria, where they were still kept in the same groups and fed the same dietary regimens. Every other day, 1 animal of a different group was randomly chosen and euthanized at about $0830 \mathrm{~h}$ to gain ruminal epithelium for the Ussing chamber measurement. Goats were euthanized 2 to $3 \mathrm{~h}$ after the morning feeding with an intravenous injection of $50 \mathrm{mg} / \mathrm{kg}$ of BW Thiopental (Thiopental Sandoz, 1-g Trockenstechampulle; Sandoz International $\mathrm{GmbH}$, Kundl, Austria) after sedation with an intravenous injection of $0.2 \mathrm{mg} / \mathrm{kg}$ of BW xylazine (Xylasol Injektionslösung für Tiere, $50 \mathrm{~mL}$; Ogris Pharma Vertriebs-Gesellschaft mbH, Wels, Austria).

\section{Sampling Procedures and Laboratory Analyses}

Feed samples were collected regularly throughout the experiment and analyzed for the nutrient composition with proximate analysis. Samples were oven dried at $50^{\circ} \mathrm{C}$ for $48 \mathrm{~h}$, and ground through a $0.75-\mathrm{mm}$ sieve to analyze the contents of DM, OM, CP, NDF, and ADF. Samples were analyzed for DM by oven drying at $100^{\circ} \mathrm{C}$ overnight and ash by combustion of samples overnight at $580^{\circ} \mathrm{C}$. Crude protein was analyzed by the Kjeldahl method (VDLUFA, 2007). The contents of NDF and ADF of the feed components were analyzed according to Van Soest et al. (1991) using the Raw Fiber Extrac- tor (Velp Scientifica, Usmate, Italy) and $\alpha$-amylase in the case of NDF analysis.

After the animals were euthanized they were immediately opened and a sample of the ventral ruminal tissue $\left(\sim 50 \mathrm{~cm}^{2}\right)$ was taken for the Ussing chamber measurement. Additionally, ruminal fluid was collected and part of it frozen at $-20^{\circ} \mathrm{C}$ for later analysis of VFA. The other part was analyzed for $\mathrm{pH}$ using the respective electrode connected to a $\mathrm{pH}$-meter (Seven Multi TM; Mettler-Toledo GmbH, Schwerzenbach, Switzerland). The VFA (acetate, propionate, butyrate, isobutyrate, valerate, and isovalerate) were analyzed by gas chromatography. Ruminal fluid samples were centrifuged at 20,000 $\times g$ for $20 \mathrm{~min}$ and the supernatant was supplemented with orthophosphoric acid and internal standard (4-methylvaleric acid). This mixture was again centrifuged at $20,000 \times g$ for $20 \mathrm{~min}$ to remove precipitated substrates. Afterward the supernatant was analyzed for VFA concentrations via gas chromatography (Fisons GC model 8060 MS DPFC, no. 950713; Fisons, Modena, Italy). The gas chromatograph was equipped with a flame-ionization detector and a $15-\mathrm{m}$ $\times$ 0.530-mm capillary column (SN US46185178; J\&W Scientific Inc., CA) was used. The temperature of the injector and detector was 170 and $190^{\circ} \mathrm{C}$, respectively. Helium was used as carrier gas with a flow rate of 1 $\mathrm{mL} / \mathrm{min}$. The sample volume was $1 \mu \mathrm{L}$ and was injected splitlessly over a sampling time of $60 \mathrm{~s}$. Graphs were designed with Stratos software (Stratos version 4.5.0.0; Polymer Laboratories Ltd., Church Stretton, UK).

Blood samples were collected on experimental d 1 (baseline sampling) and on the day of euthanasia shortly before feeding from the jugular vein using 10$\mathrm{mL}$ blood-collection tubes (Vacuette; Greiner Bio-One $\mathrm{GmbH}$, Kremsmünster, Austria). Serum was immediately separated by centrifugation at $1,800 \times g$ and $4^{\circ} \mathrm{C}$ and stored at $-80^{\circ} \mathrm{C}$ for later analyses of concentrations of LPS, BHBA, and SAA. Serum LPS was analyzed

Table 1. Ingredients and chemical composition of the experimental diets offered to the animals

\begin{tabular}{lccc}
\hline & \multicolumn{3}{c}{ Dietary treatment $^{1}$} \\
\cline { 2 - 4 } Item & $\mathrm{g} / \mathrm{kg}$ of $\mathrm{DM})$ & $\mathrm{CTR}$ & $\mathrm{HB}$ \\
\hline Ingredient & 1,000 & 695 & 395 \\
Hay & - & 305 & 605 \\
Barley grain & & & \\
Analyzed composition & 916 & 932 & 948 \\
OM & 103 & 110 & 117 \\
CP & 556 & 449 & 344 \\
NDF & 402 & 304 & 207 \\
ADF & &
\end{tabular}

${ }^{1} \mathrm{CTR}=$ hay-based control diet; $\mathrm{LB}=30 \%$ barley grain and $70 \%$ hay; $\mathrm{HB}=60 \%$ barley grain and $40 \%$ hay. 
using Pyrochrome for the kinetic chromogenic Limulus amebocyte lysate (LAL) method and the Pyros Kinetix Flex tube reader from Pyroquant Diagnostik GmbH (Mörfelden-Walldorf, Germany; Associates of Cape Cod Inc., East Falmouth, MA). Serum samples were diluted 1:3 with pyrogen-free LAL reagent water (Associates of Cape Cod Inc.). Afterward, samples were incubated at $75^{\circ} \mathrm{C}$ for $15 \mathrm{~min}$ to denaturize proteins using the Thermomixer comfort (Eppendorf Austria $\mathrm{GmbH}$, Vienna, Austria). The cooled samples were centrifuged for $10 \mathrm{~min}$ at $12,100 \times \mathrm{g}$ for protein precipitation; $200 \mu \mathrm{L}$ of the supernatant was transferred to pyrogen-free reaction tubes (Pyrotube-K; Associates of Cape Cod Inc.) and $50 \mu \mathrm{L}$ of Pyrochrome LAL reagent dissolved in Glucashield buffer (Associates of Cape Cod Inc.) was added. The Pyrochrome-sample mixture was immediately incubated at $37^{\circ} \mathrm{C}$ in a Pyros Kinetix Flex tube reader (Associates of Cape Cod Inc.). Changes in optical density of samples at $405 \mathrm{~nm}$ were measured against a calibration curve using Pyros EQS software (Associates of Cape Cod Inc.). For the quantitative determination of BHBA in blood serum, the commercially available Ranbut kit of Randox Laboratories Ltd. (Antrim, UK), based on a kinetic enzymatic method, was applied according to the protocol using the Thermomixer comfort (Eppendorf Austria GmbH) for incubation and shaking. The optical density was measured against a calibration curve at $340 \mathrm{~nm}$ with the Hitachi U-3000 spectrophotometer (Metrohm Inula GmbH Vienna, Austria). The detection limit was $0.1 \mathrm{mmol} / \mathrm{L}$. Serum amyloid A in blood serum was analyzed with the Tridelta phase range Multispecies SAA ELISA kit (Tridelta Development Ltd., Greystones, Co. Wicklow, Ireland) using the Reader iMark microplate absorbance reader (Bio-Rad Laboratories GmbH,, Vienna, Austria). Therefore, samples were diluted 1:200 in diluent buffer and the instructions of the manufacturer were followed. Samples, including the calibration curve, were incubated in microwells at $37^{\circ} \mathrm{C}$ in the Thermomixer comfort (Eppendorf Austria GmbH) together with a horseradish peroxidase (HRP) labeled anti-SAA antibody. Absorbance was measured at $450 \mathrm{~nm}$. The intraassay coefficients of variation were $<10 \%$. All reactions were run in duplicate.

\section{Determination of Clinical Health Parameters}

Animals were monitored throughout the experiment for health and distress problems from the veterinary technician. In addition, goats were subjected to a clinical examination on 5 different days during the experiment. Investigated clinical variables were pulse rate, rectal body temperature, ruminal contraction rate, and respiration rate. Pulse rate was recorded in the arteria femoralis. Breath rates and ruminal contractions were recorded using a stethoscope. Rectal temperature was measured using a digital thermometer (Thermoval; Paul Hartmann AG, Heidenheim, Germany). Furthermore, feces were evaluated by adopting a 3-scale fecal scoring system that ranged from score 1 (firm, normal feces) to score 3 (viscous, diarrhea).

\section{Ruminal Epithelia Sample Collections and Ussing Chamber Measurements}

The electrophysiological properties and permeability of the ruminal epithelium were investigated with the isolated, intact ruminal epithelium using the Ussing chamber technique. In total, 6 incubation chambers were used per animal considered as repeated measurements. The abdominal cavity was opened by midline incision and the rumen and intestinal tract were carefully removed. The rumen was opened from the dorsal side. For the experiment, a ruminal wall tissue of approximately $50 \mathrm{~cm}^{2}$ was carefully excised from the cranial part of the ventral sac. This ruminal part was chosen because of its high metabolic activity.

Immediately after obtaining the ventral rumen epithelium, it was transferred into the transport buffer solution $\left(39^{\circ} \mathrm{C}\right)$ and gassed with carbogen gas $\left(95 \% \mathrm{O}_{2}\right.$ and $\left.5 \% \mathrm{CO}_{2}\right)$ to enable respiration of the tissues. The composition of the buffer solutions is provided in Table 2. For transportation of the epithelium to the Ussing chamber laboratory, the buffer was supplemented with glucose to a final concentration of $10 \mathrm{mmol} / \mathrm{L}$. Chemicals were obtained from Sigma-Aldrich (Schnelldorf, Germany). The solutions were prepared with deionized water. For short-term storage overnight, the buffer solution was stored in a refrigerator at $4^{\circ} \mathrm{C}$. In the Ussing chamber laboratory, the ruminal wall was first cleaned by immersion in buffer solution and then the epithelium was stripped off from the muscle layer. The isolated epithelium was cut into pieces of about $2 \mathrm{~cm}^{2}$ and mounted between the 2 halves of the incubation chambers with an exposed area of $1 \mathrm{~cm}^{2}$ each. Both halves of the chambers were immediately filled with buffer solution (Table 2) and were gassed with carbogen gas $\left(95 \% \mathrm{O}_{2}\right.$ and $\left.5 \% \mathrm{CO}_{2}\right)$. Glucose was added to the serosal side and mannitol was added to the mucosal side to a final concentration of $10 \mathrm{mmol} / \mathrm{L}$ each. Buffer temperature was kept constant at $39^{\circ} \mathrm{C}$ throughout the measurement. The time elapsing from killing the goats until filling the Ussing chambers was 30 to $45 \mathrm{~min}$.

To measure epithelial permeability, fluorescein 5(6)-isothiocyanate (FITC) and HRP (e.g., McKie et al., 1999), both purchased at Sigma-Aldrich (Schnelldorf, Austria), were used as markers, representing small $(389.38 \mathrm{~g} / \mathrm{mol})$ and large $(\sim 44,000 \mathrm{~g} / \mathrm{mol})$ molecules. 
Table 2. Composition of the buffer solution used in the Ussing chamber

\begin{tabular}{lc}
\hline Compound & $\begin{array}{c}\text { Amount } \\
(\mathrm{mmol} / \mathrm{L})\end{array}$ \\
\hline $\mathrm{NaCl}$ & 80.0 \\
$\mathrm{NaHCO}_{3}$ & 25.0 \\
$\mathrm{NaH}_{2} \mathrm{PO}_{4} \times \mathrm{H}_{2} \mathrm{O}$ & 0.40 \\
$\mathrm{Na}_{2} \mathrm{HPO}_{4} \times 2 \mathrm{H}_{2} \mathrm{O}$ & 2.4 \\
$\mathrm{KCl}_{\mathrm{C}_{2} \mathrm{H}_{3} \mathrm{NaO}_{2} \times 3 \mathrm{H}_{2} \mathrm{O}}$ & 5.0 \\
$\mathrm{C}_{3} \mathrm{H}_{5} \mathrm{NaO}_{2}$ & 25.0 \\
$\mathrm{C}_{4} \mathrm{H}_{7} \mathrm{NaO}_{2}$ & 10.0 \\
$\mathrm{CaCl}_{2} \times 2 \mathrm{H}_{2} \mathrm{O}$ & 5.0 \\
$\mathrm{MgCl}_{2} \times 6 \mathrm{H}_{2} \mathrm{O}$ & 1.2 \\
\hline
\end{tabular}

After $20 \mathrm{~min}$ of equilibration of the epithelium with the buffer solution under open-circuit conditions, tissues were short-circuited and FITC (final concentration $0.2 \mathrm{mmol} / \mathrm{L}$ ) and HRP (final concentration $2 \mu \mathrm{mol} / \mathrm{L}$ ) were added to the mucosal side of each chamber and, after equilibration for $20 \mathrm{~min}$, hourly samples were taken from the serosal side to measure the flux through the epithelium. Measurements were conducted over a period of $3 \mathrm{~h}$. Continuously, transepithelial short-circuit current $\left(\mathbf{I}_{\mathrm{sc}}\right)$ as a measure of net ion transport and tissue conductance $\left(\mathbf{G}_{\mathbf{t}}\right)$ were recorded with the aid of an automatic computer-controlled voltage-clamp device (voltage/current clamp; Mussler Scientific Instruments, Aachen, Germany). The samples taken hourly from the Ussing chambers were stored at $-20^{\circ} \mathrm{C}$ and later analyzed for concentrations of FITC and HRP. The fluorescence intensity of the FITC samples was measured after dilution in water 1:5 with a fluorescence spectrometer (PerkinElmer Inc., Waltham, MA). For HRP measurement, samples from the mucosal and serosal side were diluted in PBS buffer 1:400 and 1:2, respectively. Afterward, $25 \mu \mathrm{L}$ of each sample were transferred to a microwell plate and $50 \mu \mathrm{L}$ of $3,3^{\prime}, 5,5^{\prime}$-tetramethylbenzidine liquid substrate (Sigma-Aldrich) was added. After incubation at room temperature on a shaker at 1,200 rpm for $15 \mathrm{~min}$, the reaction was stopped by adding $50 \mu \mathrm{L}$ of $0.5 \mathrm{M} \mathrm{H}_{2} \mathrm{SO}_{4}$ to each well. The absorbance of the HRP samples was measured with the iMark absorbance reader (Bio-Rad Laboratories GmbH, Munich, Germany) for comparison with the dilution series.

\section{Statistical Analyses}

All statistical analyses were carried out using PROC MIXED SAS (version 9.2; SAS Institute Inc., Cary, NC). Before analysis, all data were tested for normality by evaluating the profile of their residuals using PROC UNIVARIATE of SAS. Data were submitted to ANOVA with a model accounting for the fixed effects of diet type and the random effect of animal. For the analyses of blood variables, baseline measurements taken at the beginning of experiment were used as covariates in the analysis of covariance. Data of the clinical health variables were submitted to ANOVA considering the diet type as fixed, the animal as a random effect, and the measurements recorded at different weeks were considered as repeated measures using a first-order autoregressive variance-covariance matrix. Data of the 3 $\mathrm{h}$ measurements in the Ussing chamber were subjected to ANOVA, including diet and chamber in the model. Chambers were considered as repeated measures, animal as random and diet as fixed effects. In the case of the FITC and HRP measurements, mean values of the 6 chambers were calculated and time of sampling was considered as repeated measures with a first-order autoregressive variance-covariance matrix. Polynomial contrasts were used to test for linear and quadratic effects of increasing barley inclusion in the diet. Degrees of freedom were estimated using the method of Kenward-Roger. Multiple comparisons among means were performed with Tukey method. Means were reported as least squares means \pm standard error of the mean, with $P \leq 0.05$ defined as significant, and trends were discussed at $0.05<P \leq 0.10$.

\section{RESULTS}

\section{Ruminal Fluid and Serum Variables}

Dietary effects on ruminal fluid and serum variables are presented in Table 3. Ruminal measurements taken at the end of the experiment indicated that ruminal $\mathrm{pH}$ linearly decreased with increasing amounts of barley in the diet $(P<0.001)$, so that goat pertaining to the HB group had, on average, a $\mathrm{pH}$ value of 5.5 (Table 3 ). The concentration of propionate tended to increase with a linear dependence on barley inclusion $(P=0.059)$. Concentrations of butyrate and isobutyrate also significantly increased in response to barley inclusion (Table 3). The rest of the VFA measured remained unaffected by dietary treatment in this study.

The serum data obtained by ANOVA revealed increased LPS concentrations quadratically, depending on dietary barley inclusion $(P=0.046$; Table 3$)$; thus, the highest serum LPS concentration was found with LB $(P<0.05)$. Serum amyloid A was not affected by the inclusion of increasing amounts of barley grain in the diet. Barley inclusion tended to increase serum BHBA concentrations (linearly, $P=0.083$; quadratically, $P=0.051$; Table 3 ).

\section{Clinical Health Variables}

Results of the clinical examination are shown in Table 4. Concentrate feeding had no effect on rectal 
KLEVENHUSEN ET AL.

Table 3. Treatment effects on ruminal fluid and blood serum variables ${ }^{1}$

\begin{tabular}{|c|c|c|c|c|c|c|}
\hline \multirow[b]{2}{*}{ Variable $^{2}$} & \multicolumn{3}{|c|}{ Dietary treatment ${ }^{3}$} & \multirow[b]{2}{*}{ SEM } & \multicolumn{2}{|c|}{$P$-value ${ }^{4}$} \\
\hline & CTR & LB & $\mathrm{HB}$ & & Linear & Square \\
\hline \multicolumn{7}{|l|}{ Ruminal fluid } \\
\hline $\mathrm{pH}$ & $6.4^{\mathrm{a}}$ & $6.0^{\mathrm{a}}$ & $5.5^{\mathrm{b}}$ & 0.14 & $<0.001$ & 0.726 \\
\hline Total VFA (mmol/L) & 114 & 121 & 129 & 7.61 & 0.169 & 0.955 \\
\hline Acetate $(\mathrm{mmol} / \mathrm{L})^{\prime}$ & 81.0 & 83.2 & 77.0 & 5.55 & 0.600 & 0.518 \\
\hline Propionate (mmol/L) & 20.9 & 21.5 & 32.6 & 4.20 & 0.059 & 0.289 \\
\hline Butyrate (mmol/L) & 8.2 & 12.4 & 13.8 & 1.81 & 0.040 & 0.518 \\
\hline Isobutyrate $(\mathrm{mmol} / \mathrm{L})$ & $0.9^{\mathrm{b}}$ & $1.1^{\mathrm{b}}$ & $1.9^{\mathrm{a}}$ & 0.12 & $<0.001$ & 0.018 \\
\hline Valerate $(\mathrm{mmol} / \mathrm{L})$ & 1.9 & 1.7 & 2.0 & 0.26 & 0.732 & 0.419 \\
\hline Isovalerate (mmol/L) & 0.9 & 0.9 & 1.2 & 0.18 & 0.174 & 0.560 \\
\hline \multicolumn{7}{|l|}{ Blood serum } \\
\hline SAA $(\mu \mathrm{g} / \mathrm{mL})$ & 0.26 & 0.43 & 3.68 & 1.77 & 0.885 & 0.865 \\
\hline $\mathrm{BHBA}(\mathrm{mmol} / \mathrm{L})$ & 0.47 & 0.75 & 0.72 & 0.522 & 0.051 & 0.083 \\
\hline LPS $(\mathrm{EU} / \mathrm{mL})$ & 0.04 & 0.21 & 0.08 & 0.021 & 0.131 & 0.046 \\
\hline
\end{tabular}

$\overline{\mathrm{a}, \mathrm{b}}$ Values with different superscripts in the same row differ significantly $(P<0.05)$.

${ }^{1}$ Blood samples collected on experimental d 0 served as covariates for analysis of covariance.

${ }^{2} \mathrm{SAA}=$ serum amyloid $\mathrm{A}$; LPS was measured as endotoxic unit per milliliter $(\mathrm{EU} / \mathrm{mL})$.

${ }^{3} \mathrm{CTR}=$ hay-based control diet; $\mathrm{LB}=30 \%$ barley grain and $70 \%$ hay; $\mathrm{HB}=60 \%$ barley grain and $40 \%$ hay.

${ }^{4}$ Linear or quadratic effect of dietary treatment.

body temperature and ruminal contraction rate. However, both pulse and respiration rate were increased by barley feeding, with a difference between CTR and HB $(P<0.05)$, but not between the CTR and LB dietary treatments. Also, fecal scoring revealed an effect of barley feeding in this study. Thus, the fecal consistency of goats from the HB group decreased compared with LB and CTR groups $(P<0.05)$, but no difference was observed between the latter 2 groups (Table 4 ).

\section{Ussing Chamber Experiment}

The results of the Ussing chamber experiment regarding the electrophysiological characteristics and the permeability measurement of FITC and HRP markers across the ruminal epithelium are shown in Figure 1. The ANOVA showed that barley grain feeding significantly altered electrophysiological properties of the ruminal wall. Thus, the $I_{\mathrm{sc}}$ was higher with $\mathrm{LB}$ and
HB compared with CTR diet $(P<0.05$; Figure 1A). The ANOVA also indicated an increased $G_{t}$ with barley inclusion in the diet (Figure 1B), with a linear and quadratic dependence (both $P<0.001$ ).

Data of the flux of FITC from the mucosal to apical side of the rumen wall indicated a lower permeability with CTR compared with both barley-based diets $(P$ $<0.05$; Figure $1 \mathrm{C})$, so that the ANOVA revealed a linear dependence on barley inclusion $(P<0.05)$. The analysis also showed that the mucosal to serosal flux of HRP increased with increasing dietary barley content in the diet $(P<0.001 ;$ Figure 1D).

\section{DISCUSSION}

In the present in vivo experiment, growing goats were assigned to 1 of the 3 treatment groups with increasing supplementation of barley grain. Inclusion of $60 \%$ barley in the diet significantly lowered ruminal $\mathrm{pH}$, decreasing

Table 4. Treatment effects on clinical health parameters

\begin{tabular}{|c|c|c|c|c|c|c|}
\hline \multirow[b]{2}{*}{ Variable $^{1}$} & \multicolumn{3}{|c|}{ Dietary treatment ${ }^{2}$} & \multirow[b]{2}{*}{ SEM } & \multicolumn{2}{|c|}{$P$-value ${ }^{3}$} \\
\hline & CTR & LB & $\mathrm{HB}$ & & Linear & Square \\
\hline Pulse rate (beats/min) & $96.0^{\mathrm{b}}$ & $105^{\mathrm{ab}}$ & $118^{\mathrm{a}}$ & 4.77 & 0.005 & 0.764 \\
\hline Body temperature $\left({ }^{\circ} \mathrm{C}\right)$ & 39.1 & 39.1 & 39.3 & 0.09 & 0.128 & 0.544 \\
\hline Respiration rate (breaths/min) & $27.3^{\mathrm{b}}$ & $30.1^{\mathrm{ab}}$ & $30.5^{\mathrm{a}}$ & 0.86 & 0.015 & 0.218 \\
\hline Ruminal contraction rate $(/ 5 \mathrm{~min})$ & 6.7 & 7.1 & 7.0 & 0.39 & 0.470 & 0.502 \\
\hline Fecal score & $1.1^{\mathrm{b}}$ & $1.1^{\mathrm{b}}$ & $1.3^{\mathrm{a}}$ & 0.05 & 0.005 & 0.130 \\
\hline
\end{tabular}



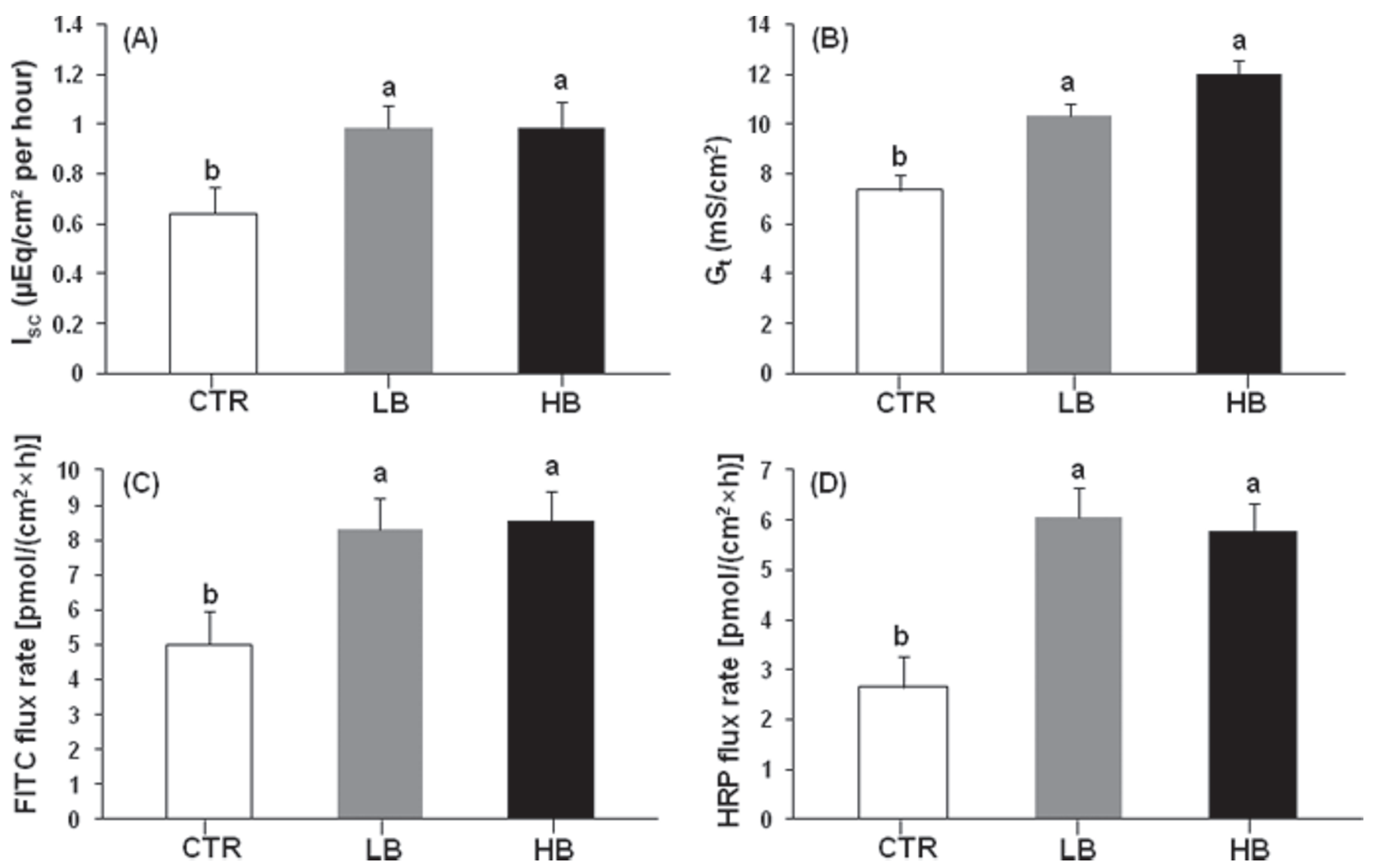

Figure 1. Dietary treatment effects on the electrophysiological properties $(A)$ short-circuit current $\left(I_{\mathrm{sc}}\right)$, $(B)$ tissue conductance $\left(\mathrm{G}_{\mathrm{t}}\right)$, tissue permeability as measured as flux rate of (C) fluorescein 5(6)-isothiocyanate (FITC) and (D) horseradish peroxidase $(\mathrm{HRP})$. CTR $=$ hay-based control diet; $\mathrm{LB}=30 \%$ barley grain and $70 \%$ hay; $\mathrm{HB}=60 \%$ barley grain and $40 \%$ hay. Values with different letters (a and $\mathrm{b}$ ) differ significantly $(P<0.05)$. Error bars represent the standard error of the mean $(\mathrm{SEM})$.

below values of 5.8 in almost all animals pertaining to this dietary treatment. Ruminal $\mathrm{pH}$ values of $<5.8$ and, most importantly, the time duration during which ruminal $\mathrm{pH}$ is $<5.8$ is often referred to as a critical threshold for SARA in dairy cows (Zebeli et al., 2008). Although the duration of ruminal $\mathrm{pH}$ below 5.8 and, hence, the duration of acidotic conditions is not known in this study, the data of ruminal $\mathrm{pH}$ measured at 2 to $3 \mathrm{~h}$ postfeeding indicate that animals fed the HB diet were at a higher risk of SARA than those fed the LB diet. Animals of the latter group had a ruminal $\mathrm{pH}$ of 6.0; however, because measurements in this study were conducted at 2 to $3 \mathrm{~h}$ postfeeding, a depression of ruminal $\mathrm{pH}$ below 5.8 later after the feeding cannot be excluded for goats fed the LB diet.

The linear decline in ruminal $\mathrm{pH}$ with increasing amounts of barley grain inclusion in the diet may partly be related to increased lactate production in the rumen in response to barley grain feeding (Ametaj et al., 2010b). Another explanation for the decreasing ruminal $\mathrm{pH}$ could be an increased production rate of total
VFA with an associated release of protons. Although the concentrations of total VFA remained rather unaffected by diet type, the production rate of VFA may not always be reflected by their molar concentrations in the rumen. The latter are additionally influenced by absorption across the ruminal epithelium (Aschenbach et al., 2011).

Electrophysiological data, especially an increased capacity for net charge transfer (i.e., $\mathrm{I}_{\mathrm{sc}}$ ), indicate that a long-term adaptation of the epithelium may have occurred in goats in the present study, which may have balanced the ruminal concentration of total VFA. An increased capacity for VFA absorption has previously been demonstrated by Gäbel et al. (1991) following adaptation of sheep to a high-grain diet. Such adaptation can be achieved by increasing the size of papillae in response to high-grain feeding to maximize the surface area for VFA absorption (Gaebel et al., 1987) and by an increase in the absorption rate (Gäbel et al., 2002) due to altered expression of genes involved in the metabolism of VFA of individual ruminal epi- 
thelial cells (Penner et al., 2011). In this respect, the enhanced intraruminal proportions of propionate and butyrate, as expected when high-starch diets are fed, could also be of relevance. Especially butyrate, which was linearly enhanced with barley feeding, is known to be an important stimulus for ruminal epithelial maturation and adaptation (Gäbel et al., 2002; Plöger et al., 2012). However, together with decreasing ruminal $\mathrm{pH}$, as during SARA, an excess of butyrate production is suspected to be toxic (Plöger et al., 2012), and can cause para- and hyperkeratosis (Gäbel et al., 2002), thus being detrimental for the ruminal barrier function. To prevent this, butyrate from ruminal fermentation is quickly oxidized to the ketone body BHBA during alimentary ketogenesis (Gäbel et al., 2002). $\beta$-Hydroxybutyrate, in turn, serves as an important energy source for growing animals and precursor of milk FA in dairy ruminants (Gäbel et al., 2002). Thus, as the ruminal butyrate concentrations were enhanced when barley was part of the diet, it seems only reasonable that blood BHBA concentrations also increased due to an enhanced alimentary ketogenesis, which has already been observed earlier (Kristensen et al., 2000). Other studies exist that are in agreement with the present experiment, observing enhanced BHBA concentrations with increased amounts of starch in the diet (Ametaj et al., 2009; Owens et al., 2009; Zebeli et al., 2011).

Data also showed that SAA concentration in the serum remained unaffected despite lowered ruminal $\mathrm{pH}$ and higher serum LPS with LB and increased $\mathrm{I}_{\mathrm{sc}}$ and $G_{t}$ of the ruminal epithelium in response to barley grain inclusion. Serum amyloid A is an APP synthesized by hepatocytes during infection, inflammation, and tissue injury (Jensen and Whitehead, 1998). Several authors have reported enhanced concentrations of SAA in plasma when SARA was induced by increasing grain inclusion in the diet of dairy cows (Emmanuel et al., 2008; Khafipour et al., 2009a) and steers (Gozho et al., 2006). One explanation for our observations might be that the goats in the HB group did not suffer from systemic inflammation despite of the low $\mathrm{pH}$, because of the long period of feeding the high-concentrate diet, which might have enabled adaptation of the epithelium to acidic conditions (Gäbel et al., 2002). It may also be that SARA of the present study was not strong enough to elicit a systemic APR. Indeed, the study by Khafipour et al. (2009b), using alfalfa hay pellets to induce SARA, showed that a depression in ruminal $\mathrm{pH}$ and high ruminal LPS do not necessarily cause systemic inflammation. Apparently, the origin of LPS (Plaizier et al., 2012; i.e., the ruminal bacterial populations) and the presence of other chemicals such as alcohols and biogenic amines (Ametaj et al., 2010a), which also depend on the diet, strongly affect the immunogenic properties of LPS and the extent of APR (Zebeli and Metzler-Zebeli, 2012).

Present findings of unchanged SAA concentrations agree with observations from previous similar studies in goats. For example, a recent study by González et al. (2010) also reported unaffected plasma SAA in goats fed either forage-based or $60 \%$ grain-based diets, despite lowered ruminal $\mathrm{pH}$ (on average, 5.5) and greater concentrations of plasma haptoglobin, another APP, in grain-fed goats. Further studies are warranted to clarify whether haptoglobin or SAA is a more accurate marker of the inflammation in goats fed large amounts of grain.

Despite no clear signs of systemic inflammation, the ruminal epithelium was affected by barley feeding, as revealed by the results of the Ussing chamber experiment. Accordingly, the high barley inclusion in the diet increased $I_{s c}$ and $G_{t}$ of the ruminal epithelium of goats and increased the permeability through the ruminal wall of the marker molecules FITC and HRP. Both the measured $I_{s c}$ and $G_{t}$ indicate an increased ion flow across either the transcellular or the paracellular route. Paracellular permeability can be measured by the transepithelial transport of molecules, which usually are not present in the extracellular domain. Thus, the measured rise in $I_{s c}$ and $G_{t}$, coupled with enhanced permeability to FITC and HRP, indicate a decreased epithelial barrier function. The increased permeability and ion exchange potential of ruminal epithelia observed in this study in response to grain feeding might also be a compensatory reaction of the ruminal epithelia to lower the luminal load of fermentation acids by increasing transepithelial ion transport (Zebeli and Metzler-Zebeli, 2012). It is, however, not clear if this process may have also led to an impairment of the selective barrier function of the ruminal epithelia, allowing translocation of larger molecules such as HRP from the mucosal to the serosal side. In fact, rumen epithelial barrier function can be considered as selective, as paracellular transport follows the electrochemical gradient and depends also on the molecules' sizes and their charges (Gäbel et al., 2002).

The ruminal barrier is crucial to prevent the translocation of LPS and other toxins or bacteria into the portal circulation (Penner et al., 2011). Subacute ruminal acidosis is considered as the main reason leading to a decrease in barrier function of the ruminal wall (Penner et al., 2011). Penner et al. (2010) found that an induced mild episode of SARA in sheep had no effect on the barrier function of ruminal epithelia measured in Ussing chambers using $\mathrm{H}^{3}$-labeled mannitol as marker. However, in vitro they observed that a rapid and more severe acidification ( $\mathrm{pH} 5.2$ ) increased epithelial permeability. Emmanuel et al. (2007) found strongly increased permeability for mannitol at a low $\mathrm{pH}$ of 4.5 in the presence of LPS, whereas no effect was found at a $\mathrm{pH}$ of 
5.5 or higher. Both studies indicate in vitro short-term effects of acidification on the permeability of ruminal tissue, but in vivo results of long-term effects of rumen acidification on permeability are missing.

Although the $\mathrm{pH}$ value was measured only on the last experimental day, one might assume a dietary effect throughout the experiment, meaning acidic ruminal conditions with the barley-based diets. Accordingly, after that time epithelial permeability was increased in the barley groups, probably as a result of epithelial damage due to low ruminal pH (Aschenbach and Gäbel, 2000). Additionally, increased LPS release in the rumen or hindgut during lyses of gram-negative bacteria exposed to acidic conditions might have contributed to epithelial damage (Li et al., 2012; Plaizier et al., 2012), which might be supported by the results of serum LPS, which were quadratically affected by barley feeding and, thus, were highest with the LB diet. Although rumen LPS was not recorded in this study, the rise of plasma LPS allows the assumption that luminal LPS (rumen or hindgut LPS, or both) also increased in goats fed grain-rich diets. It is known that LPS translocated into blood might also come from the hindgut fermentation in cows fed grain-rich diets (Li et al., 2012), although other sources of systemic LPS, including infections from gram-negative bacteria, are also reported in the literature (Ametaj et al., 2010a).

The $I_{s c}$, as a measure of active ion transfer, as well as the $G_{t}$ (i.e., passive ion leak) increased when barley was part of the diet. The study by Aschenbach and Gäbel (2000) also found increased $G_{t}$ after acidification in vitro, whereas data reported by Penner et al. (2010) demonstrated that increases in $G_{t}$ can especially be expected in the early recovery phase from an acidotic insult. However, the studies investigated the short-term effect of direct acidification in vitro (i.e., they decreased the $\mathrm{pH}$ value directly in the Ussing chamber experiment). In the present study, the animals were fed the experimental diet over a long period; accordingly, the low ruminal $\mathrm{pH}$ value with the $\mathrm{HB}$ diet probably existed for several weeks. Thus, our results clearly demonstrate a long-term dietary effect on the electrophysiological properties and the permeability of the ruminal epithelium with decreased barrier function due to high-barley grain feeding.

Clinical data of the present study showed that both pulse and respiration rate increased, in a linear fashion, in response to dietary barley inclusion. Although significant differences were observed compared with controls, the values reported for animals fed barley were within the normal clinical range and cannot be considered as abnormal and indicators of health disturbances. However, these findings indicate stress for the animals due to grain feeding, which has been observed earlier in cases of SARA in beef cattle (Leedle et al., 1995). The study by Nour et al. (1998) reported increased pulse and respiration rate in goats when acute lactic acidosis was induced, depending on the time after infusion of sorghum flour. In comparison, though, the values before infusion were lower than the values of the CTR animals in the present study and, thus, the observed increase in pulse and respiration rate was considerably higher than in the present study. In most animals they also observed clear signs of diarrhea, which was not the case in the present study. Differences in the fecal consistency between these 2 studies can be explained by a greater severity of acidosis in the study by Nour et al. (1998) compared with our study. Nevertheless, fecal scores also increased with barley feeding, indicating a lowered consistency of feces fed greater amounts of barley. Although goats in our study did not show signs of diarrhea, and although the description of fecal consistency in goats is different from that of cattle, it has been reported that intermittent diarrhea in cattle can be a clinical sign for SARA with an additionally increased particle size (Kleen et al., 2003). Indeed, feeding increasing amounts of grain also increased the proportion of large particles in rumen digesta in the current study (results not shown), which may indicate a lowered comminution of feed particles, due likely to either disturbed rumen conditions or chewing activity. Impaired ruminal functioning in terms of rumination, bacterial breakdown, and passage has been reported to lead to changes in fecal rigidity (Kleen et al., 2003).

\section{CONCLUSIONS}

The results of the present experiment demonstrate that, although feeding the HB diet over 6 wk lowered ruminal $\mathrm{pH}$ to a value that is considered as the SARA threshold, no signs of inflammation became apparent, as blood SAA concentrations remained unaffected by the diet. However, despite the lack of inflammation, high-concentrate feeding significantly altered the electrophysiological properties and increased the permeability of the ruminal epithelium, thereby possibly making it more susceptible for toxin transfer into the systemic circulation. Further studies are warranted to clarify the role of barley inclusion in the development of SARA in relation to ruminal epithelial damage, translocation of endotoxins in vivo, and their consequences for long-term animal health.

\section{ACKNOWLEDGMENTS}

The assistance of A. Dockner, M. Finsterböck, B. Glaser, C. von Reitzenstein, R. Tienken, S. Wetzels (Vetmeduni Vienna, Vienna, Austria), N. Jahan (Catholic 
University of Piacenza "Sacro Cuore," Piacenza, Italy), and K. Wolf (Free University of Berlin, Berlin, Germany) with feeding, sampling, laboratory analyses and, in particular, with the Ussing chamber experiment as well as the analyses of the FITC and HRP is gratefully acknowledged. We are thankful to H. Weissenböck and his team (Institute of Veterinary Pathology, Vetmeduni Vienna) for their help with the rumen sampling, and to the staff of the Institute for Organic Farming and Biodiversity (LFZ Raumberg-Gumpenstein, Wels, Austria) and the Clinic for Ruminants (Vetmeduni Vienna) for the care of the experimental goats.

\section{REFERENCES}

Ametaj, B. N., D. G. Emmanuel, Q. Zebeli, and S. M. Dunn. 2009. Feeding high proportions of barley grain in a total mixed ration perturbs diurnal patterns of plasma metabolites in lactating dairy cows. J. Dairy Sci. 92:1084-1091.

Ametaj, B. N., Q. Zebeli, and S. Iqbal. 2010a. Nutrition, microbiota, and endotoxin-related diseases in dairy cows. R. Bras. Zootec. 39:433-444.

Ametaj, B. N., Q. Zebeli, F. Saleem, N. Psychogios, M. J. Lewis, S. M. Dunn, J. Xia, and D. S. Wishart. 2010b. Metabolomics reveals unhealthy alterations in rumen metabolism with increased proportion of cereal grain in the diet of dairy cows. Metabolomics 6:583-594.

Aschenbach, J. R., and G. Gäbel. 2000. Effect and absorption of histamine in sheep rumen: Significance of acidotic epithelial damage. J. Anim. Sci. 78:464-470.

Aschenbach, J. R., G. B. Penner, F. Stumpff, and G. Gäbel. 2011. Ruminant Nutrition Symposium: Role of fermentation acid absorption in the regulation of ruminal pH. J. Anim. Sci. 89:1092-1107.

Emmanuel, D. G. V., S. M. Dunn, and B. N. Ametaj. 2008. Feeding high proportions of barley grain stimulates an inflammatory response in dairy cows. J. Dairy Sci. 91:606-614.

Emmanuel, D. G. V., K. L. Madsen, T. A. Churchill, S. M. Dunn, and B. N. Ametaj. 2007. Acidosis and lipopolysaccharide from Escherichia coli B:055 cause hyperpermeability of rumen and colon tissues. J. Dairy Sci. 90:5552-5557.

Gäbel, G., J. R. Aschenbach, and F. Müller. 2002. Transfer of energy substrates across the ruminal epithelium: Implications and limitations. Anim. Health Res. Rev. 3:15-30.

Gäbel, G., M. Bestmann, and H. Martens. 1991. Influences of diet, short-chain fatty acids, lactate and chloride on bicarbonate movement across the reticulo-rumen wall of sheep. Zentralbl. Veterinarmed. A 38:523-529.

Gaebel, G., H. Martens, M. Suendermann, and P. Galfi. 1987. The effect of diet, intraruminal $\mathrm{pH}$ and osmolarity on sodium, chloride and magnesium absorption from the temporarily isolated and washed reticulo-rumen of sheep. Q. J. Exp. Physiol. 72:501-511.

Gesellschaft für Ernährungsphysiologie. 2003. Recommendations for the supply of energy and nutrients to goats. DLG-Verlag, Frankfurt am Main, Germany.

González, F. H. D., F. H. Ruipérez, J. M. Sánchez, J. C. Souza, S. Martínez-Subiela, and J. J. Cerón. 2010. Haptoglobin and serum amyloid $\mathrm{A}$ in subacute ruminal acidosis in goats. Revista de la Facultad de Medicina Veterinaria y de Zootecnia 57:159-167.

Gozho, G. N., D. O. Krause, and J. C. Plaizier. 2006. Rumen lipopolysaccharide and inflammation during grain adaptation and subacute ruminal acidosis in steers. J. Dairy Sci. 89:4404-4413.

Jensen, L. E., and A. S. Whitehead. 1998. Regulation of serum amyloid A protein expression during the acute-phase response. Biochem. J. 334:489-503.

Khafipour, E., D. O. Krause, and J. C. Plaizier. 2009a. A grain-based subacute ruminal acidosis challenge causes translocation of lipo- polysaccharide and triggers inflammation. J. Dairy Sci. 92:10601070.

Khafipour, E., D. O. Krause, and J. C. Plaizier. 2009b. Alfalfa pelletinduced subacute ruminal acidosis in dairy cows increases bacterial endotoxin in the rumen without causing inflammation. J. Dairy Sci. 92:1712-1724.

Kleen, J. L., G. A. Hooijer, J. Rehage, and J. P. T. M. Noordhuizen. 2003. Subacute ruminal acidosis (SARA): A review. J. Vet. Med A Physiol. Pathol. Clin. Med. 50:406-414.

Kristensen, N. B., S. G. Pierzynowski, and A. Danfær. 2000. Portaldrained visceral metabolism of 3-hydroxybutyrate in sheep. J. Anim. Sci. 78:2223-2228.

Leedle, J. A., M. L. Coe, and R. A. Frey. 1995. Evaluation of health and ruminal variables during adaptation to grain-based diets in beef cattle. Am. J. Vet. Res. 56:885-892.

Li, S., E. Khafipour, D. O. Krause, A. Kroeker, J. C. RodriguezLecompte, G. N. Gozho, and J. C. Plaizier. 2012. Effects of subacute ruminal acidosis challenges on fermentation and endotoxins in the rumen and hindgut of dairy cows. J. Dairy Sci. 95:294-303.

McKie, A. T. P. S. Zammit, and R. J. Naftalin. 1999. Comparison of cattle and sheep colonic permeabilities to horseradish peroxidase and hamster scrapie prion protein in vitro. Gut 45:879-888.

Nour, M. S. M., M. T. Abusamra, and B. E. D. Hago. 1998. Experimentally induced lactic acidosis in Nubian goats: Clinical, biochemical and pathological investigations. Small Rumin. Res. $31: 7-17$.

Owens, D., M. McGee, T. Boland, and P. O'Kiely. 2009. Rumen fermentation, microbial protein synthesis, and nutrient flow to the omasum in cattle offered corn silage, grass silage, or whole-crop wheat. J. Anim. Sci. 87:658-668.

Penner, G. B., M. Oba, G. Gäbel, and J. R. Aschenbach. 2010. A single mild episode of subacute ruminal acidosis does not affect ruminal barrier function in the short term. J. Dairy Sci. 93:4838-4845.

Penner, G. B., M. A. Steele, J. R. Aschenbach, and B. W. McBride. 2011. Ruminant Nutrition Symposium: Molecular adaptation of ruminal epithelia to highly fermentable diets. J. Anim. Sci 89:1108-1119

Plaizier, J. C., E. Khafipour, S. Li, G. N. Gozho, and D. O. Krause. 2012. Subacute ruminal acidosis (SARA), endotoxins and health consequences. Anim. Feed Sci. Technol. 172:9-21.

Plöger, S., F. Stumpff, G. B. Penner, J.-D. Schulzke, G. Gäbel, H Martens, Z. Shen, D. Günzel, and J. R. Aschenbach. 2012. Microbial butyrate and its role for barrier function in the gastrointestinal tract. Ann. N. Y. Acad. Sci. 1258:52-59.

Steele, M. A., O. AlZahal, S. E. Hook, J. Croom, and B. W. McBride. 2009. Ruminal acidosis and the rapid onset of ruminal parakeratosis in a mature dairy cow: A case report. Acta Vet. Scand. 51:39.

Steele, M. A., J. Croom, M. Kahler, O. AlZahal, S. E. Hook, K. Plaizier, and B. W. McBride. 2011. Bovine rumen epithelium undergoes rapid structural adaptations during grain-induced subacute ruminal acidosis. Am. J. Physiol. Regul. Integr. Comp. Physiol 300:R1515-R1523.

Van Soest, P. J., J. B. Robertson, and B. A. Lewis. 1991. Methods for dietary fiber, neutral detergent fiber, and nonstarch polysaccharides in relation to animal nutrition. J. Dairy Sci. 74:3583-3597.

VDLUFA (Verband Deutscher Landwirtschaftlicher Untersuchungsund Forschungsanstalten). 2007: Handbuch der Landwirtschaftlichen Versuchs- und Untersuchungsmethodik (VDLUFA-Methodenbuch), Bd. III. Die Chemische Untersuchung von Futtermitteln. VDLUFA-Verlag, Darmstadt, Germany.

Zebeli, Q., J. Dijkstra, M. Tafaj, H. Steingass, B. N. Ametaj, and W. Drochner. 2008. Modeling the adequacy of dietary fiber in dairy cows based on the responses of ruminal $\mathrm{pH}$ and milk fat production to composition of the diet. J. Dairy Sci. 91:2046-2066.

Zebeli, Q., S. M. Dunn, and B. N. Ametaj. 2011. Perturbations of plasma metabolites correlated with the rise of rumen endotoxin in dairy cows fed diets rich in easily degradable carbohydrates. J. Dairy Sci. 94:2374-2382.

Zebeli, Q., and B. U. Metzler-Zebeli. 2012. Interplay between rumen digestive disorders and diet-induced inflammation in dairy cattle. Res. Vet. Sci. 93:1099-1108. 